\title{
Short versus long video-based lectures as a tool for faculty development during COVID-19 pandemic
}

\author{
Ayman Z. Elsamanoudy ${ }^{1,2}$, Rasha A. Aboukamer ${ }^{3}$, Mohammed A. Hassanien ${ }^{4,5 *}$
}

\begin{abstract}
${ }^{1}$ Department of Clinical Biochemistry, ${ }^{3}$ Department of Medical Microbiology and Parasitology, Faculty of Medicine, ${ }^{4}$ Department of pharmacy practice, Faculty of Pharmacy, King Abdulaziz University, Jeddah, Saudi Arabia ${ }^{2}$ Department of Medical Biochemistry and Molecular Biology, Faculty of Medicine, Mansoura University, Mansoura, Egypt

${ }^{5}$ Department of Medical Biochemistry, College of Medicine, Tanta University, Egypt
\end{abstract}

Received: 24 March 2021

Revised: 15 April 2021

Accepted: 16 April 2021

\section{*Correspondence:}

Dr. Mohammed A. Hassanien,

E-mail: mohammedhassanien700@yahoo.com

Copyright: $(\odot)$ the author(s), publisher and licensee Medip Academy. This is an open-access article distributed under the terms of the Creative Commons Attribution Non-Commercial License, which permits unrestricted non-commercial use, distribution, and reproduction in any medium, provided the original work is properly cited.

\begin{abstract}
With emerge of the COVID-19 pandemic, video-based lectures (VBLs) was widely used as an effective online faculty development tool. VBLs varies from short videos (5-minute) to the long one (1-2 hours). So, the current study aims to evaluate the effectiveness of long VBLs versus short VBLs. A total of 21 short (9) and long (12) VBLs were produced, in 2020, by the authors. The metadata for all of VBLs was downloaded from YouTube [VBLs overview data, audiences' engagement data, and audience retention (AR) report]. The viewership data included the number of views (4800), watch time by hours (173.6), males to females' ratio (79/21), the number of the subscribers (157), the video length $(2.9 \pm 1.2$ minutes), number of viewers $(241.1 \pm 157.8)$, and the watch time (5.1 \pm 3.3 hours). The audience retention is presented as average view duration (1.1 \pm 0.4 hours) and average percentage view $(42.8 \pm 7.9 \%)$. Lastly, audience engagement is represented by the number of subscribers (6.4 \pm 7.4$)$, likes $(9.7 \pm 8.0)$, and dislikes $(0.3 \pm 0.7)$. The comparison of the mean audience retention and engagement between short and long VBLs showed that short VBLs had significantly higher number of subscribers and likes as well as the average percentage views in comparison to long VBLs. We could conclude that short VBLs are more effective and efficient as a regard audience retention and engagement. Moreover, the more use of advanced technology for video development makes it more engaging.
\end{abstract}

Keywords: Video-based lectures, Faculty development, COVID-19

\section{INTRODUCTION}

Faculty development in professional healthcare education is defined as the activities in which faculty members participate to improve their knowledge and skills as educators, leaders, researchers, and scholars. ${ }^{1}$ So, faculty development became an important component of the field of medical education. Faculty development could use either formal or non-formal programs. Official instituteorganized workshops, seminars, and fellowships are considered as formal programs while work-based and community-based learning of practice are considered as non-formal programs with the informal learning opportunities that take place in genuine environments take a priority over the formal one., ${ }^{2,3}$

Online faculty training takes the advantages of saving time and break geographic boundaries as well as develop the experience of self-directed learning ability and it is more convenient with the current situation of COVID-19 Lockdown and social distancing measures. ${ }^{4}$ 
Online faculty development may take different forms and varies from being synchronous and asynchronous. One of the most common tools of asynchronous online faculty development is the video-based lectures (VBLs). ${ }^{5}$

VBLs may take different forms with different duration. ${ }^{6}$ Regarding duration, VBLs varies from short videos which are not more than a 5-minute duration to the long one which may reach to one or two hours in recorded lectures or webinars. Audience retention which could be measured by how well VBLs could maintain viewer attention may vary according to the length of VBLs. Video hosting platforms like YouTube gives useful information about audience retention including average view duration for each video on the channel, the average percentage viewed of each video, and the final audience retention, which is the percentage of viewers who completed the video in its entirety compared to the initial total watching at 30 seconds. ${ }^{7}$

With the emerge of the COVID-19 pandemic, VBLs was widely used as an effective online faculty development tool, the current study aims to evaluate the effectiveness of long VBLs versus short VBLs with the emphasis on the comparison audience retention parameters derived from YouTube learning analytic reports.

\section{SUBJECTS AND METHODS}

A total of 21 short and long VBLs were produced, in the year 2020, by the authors. ScreenFlow for Mac to capture and (VBLs) edit videos, besides zoom application was used to record lectures and save them in the form of the MP4 format. PowToon is the application used to create short videos with embedded animation and recorded narration. ScreenFlow has the option to combine screen video capture with speaker video recording for simultaneous viewing in the same video. YouTube channel was the video hosting platform of these videos, https://www.youtube.com/user/mhassanien2 (Figure 1).

The audiences of VBLs are faculty members in different health profession colleges in the region. The link of each video was shared by different means including WhatsApp groups of interested medical educationists, emails, etc. VBL duration varied from nine to twenty-seven minutes. The topics of VBLs are mainly related to online learning as the year 2020 was the year of paradigm shift from face to face to online learning due to COVID-19 pandemic and the emerging needs of faculty members to develop their online teaching skills, using different tools and strategies of online assessment and acquiring the required skills for using different technology tools of online learning. The metadata for all of VBLs was downloaded from YouTube, these data include VBLs overview data, audiences' engagement data, and audience retention (AR) report.

The collected data consisted of viewership data such as Total numbers of videos, top geographic viewing, the gender ratio of viewers, total viewing hours, and the number of YouTube channel subscribers. Descriptive data were also downloaded like: watch time in minutes and length of each video. Data of viewers' engagement were included, such as the number of video likes, video dislikes, and the number of new subscribers for each video. Regarding evaluating audience retention and assessing how videos could maintained viewer attention, the following data was downloaded from learning analytics data of YouTube: average view duration and average percentage view.

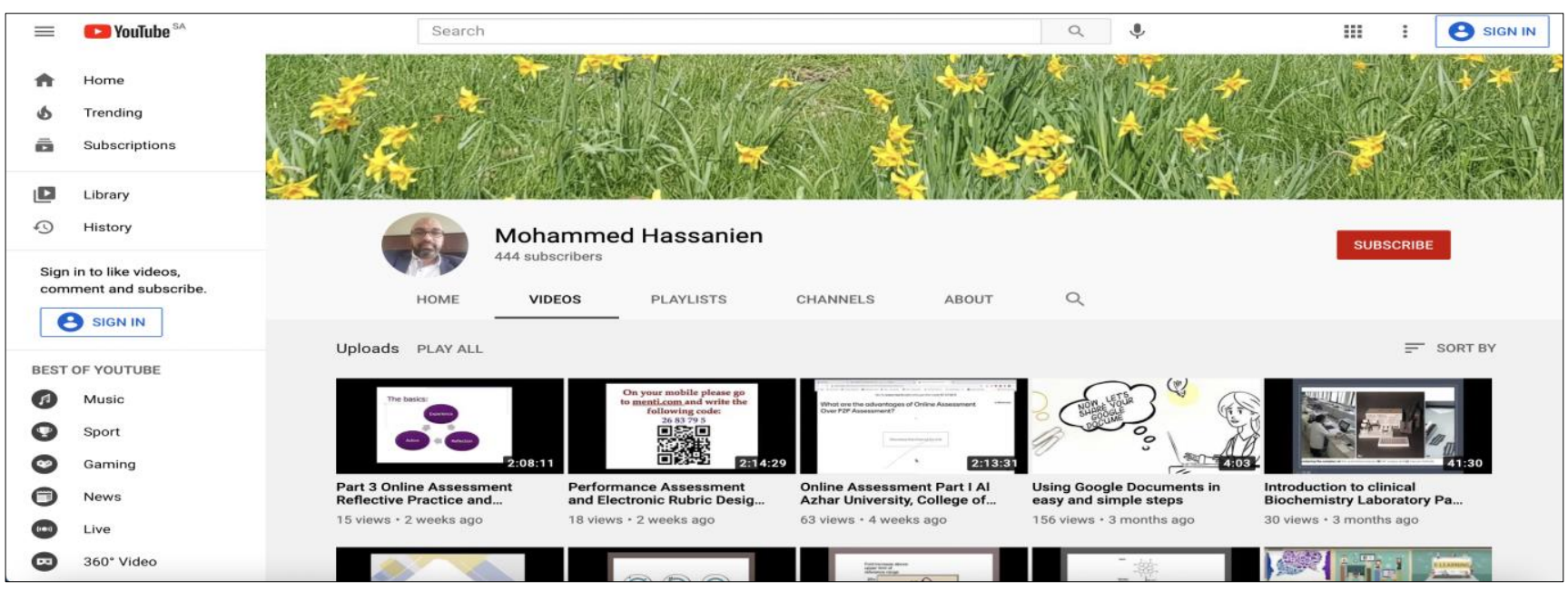

Figure 1: Author's YouTube channel (https://www.youtube.com/user/mhassanien2).

To compare short and long VBLs with audiences' engagement and retention, data were statistically analyzed using minitab 19 for Mac. All data are expressed as mean \pm standard deviation. The difference between the two means was analyzed using the student's t-test. Significance was indicated by $\mathrm{p}<0.05$. 


\section{RESULTS}

The viewership data of the YouTube channel over the year 2020 , including the total number of videos (21), views (4800), Watch time by hours (173.6), males to females' ratio of viewers $(79 / 21)$, and the number of YouTube channel subscribers (157) are presented in Table 1 and Figure 2. The percentage of viewers concerning countries viewing is illustrated in Figure 3 with the highest percentage in Saudi Arabia (19.5\%) and the lowest percentage in India (1.4\%). All of these data reflect the easy accessibility of VBLs (Table 1, Figure 2 and 3 ).

Table 1: Viewership data for all VBLs in the year 2020.

\begin{tabular}{|ll|}
\hline Parameter & N \\
\hline Total no of videos & 54 \\
\hline Total number of views & 4800 \\
\hline Watch time by hours & 173.6 \\
\hline Male/female ratio of viewers & $79 / 21$ \\
\hline $\begin{array}{l}\text { Total number of YouTube channel } \\
\text { subscribers }\end{array}$ & 157 \\
\hline
\end{tabular}

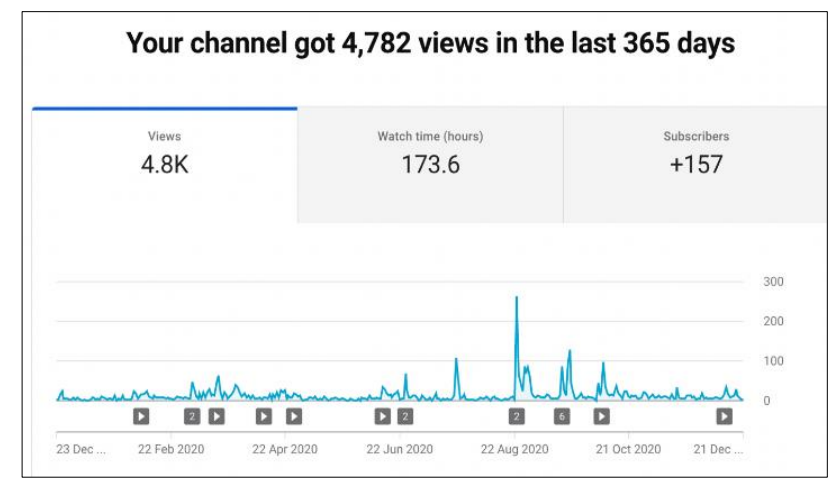

Figure 2: Screen capture from YouTube learning analytics for viewership data (viewership overview).

The descriptive data for short video lectures (9 VBLs) are illustrated in Table 2 and include the titles, the data for the overview, the audience retention, and audience engagement. Regarding data for the overview that are presented as mean $\pm \mathrm{SD}$, it shows video length $(2.9 \pm 1.2$ minutes), number of viewers $(241.1 \pm 157.8)$, and the watch time $(5.1 \pm 3.3$ hours). The audience retention is presented in two variables: average view duration $(1.1 \pm 0.4$ hours $)$ and average percentage view $(42.8 \pm 7.9 \%)$. Lastly, audience engagement is represented by the number of subscribers (6.4 \pm 7.4$)$, likes $(9.7 \pm 8.0)$, and dislikes $(0.3 \pm 0.7)$ (Table 2).

\begin{tabular}{|c|c|c|}
\hline \multicolumn{3}{|c|}{ Top geographies } \\
\hline Views - Last 3 & & \\
\hline Saudi Arabia & $\rightarrow$ & $19.5 \%$ \\
\hline Egypt & 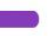 & $15.6 \%$ \\
\hline Libya & - & $2.5 \%$ \\
\hline India & $\bullet$ & $1.4 \%$ \\
\hline
\end{tabular}

Figure 3: Screen capture from YouTube learning analytics for viewership data (top geographics).

The descriptive data of the long videos (13 VBLs) are presented in Table 3 . The data are also presented as mean \pm SD. it shows video length $(43.5 \pm 34$.1 minutes $)$, number of viewers $(71.3 \pm 89.2)$, and the watch time $(3.7 \pm 4.8$ hours). The audience retention is presented in two variables: average view duration $(2.9 \pm 1.7$ hours $)$ and average percentage view $(10.9 \pm 7.2 \%)$. Lastly, audience engagement is represented by the number of subscribers

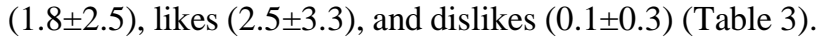

The comparison of the mean audience retention and engagement between short and long VBLs is presented in Table 4. Short VBLs show a significantly higher number of subscribers and likes ( $\mathrm{p}=0.000$ and 0.03 respectively) as well as the average percentage views $(\mathrm{p}=0.000)$ in comparison to long VBLs (Table 4).

Table 2: The descriptive data of short VBLs.

\begin{tabular}{|c|c|c|c|c|c|c|c|c|}
\hline \multirow[b]{2}{*}{ Short video title } & \multicolumn{3}{|l|}{ Overview } & \multicolumn{2}{|c|}{ Audience retention } & \multicolumn{3}{|c|}{ Engagement } \\
\hline & $\begin{array}{l}\text { Video } \\
\text { length } \\
\text { (minutes) }\end{array}$ & $\begin{array}{l}\text { View } \\
\text {-ers }\end{array}$ & $\begin{array}{l}\text { Watch } \\
\text { time } \\
\text { (hours)* }\end{array}$ & $\begin{array}{l}\text { Average } \\
\text { view } \\
\text { duration }\end{array}$ & $\begin{array}{l}\text { Average } \\
\text { percentag } \\
\text {-e view }\end{array}$ & $\begin{array}{l}\text { Subsc } \\
\text { - } \\
\text { ribers }\end{array}$ & $\begin{array}{l}\text { Li- } \\
\text { ke }\end{array}$ & $\begin{array}{l}\text { Disl } \\
\text {-ike }\end{array}$ \\
\hline $\begin{array}{l}\text { Using Google documents in easy } \\
\text { and simple steps }\end{array}$ & 4.03 & 153 & 4.3 & 1.41 & 41.9 & 7 & 9 & 0 \\
\hline $\begin{array}{l}\text { Competencies of online teaching } \\
\text { (KAU) }\end{array}$ & 4.39 & 316 & 8.5 & 1.36 & 34.6 & 19 & 22 & 0 \\
\hline $\begin{array}{l}\text { Using } \mathrm{ZOOM} \text { to create breakout } \\
\text { rooms in minutes }\end{array}$ & 3.49 & 260 & 5.8 & 1.2 & 35.3 & 6 & 13 & 0 \\
\hline $\begin{array}{l}\text { Using zoom for creating video } \\
\text { audio lecture in } 2 \text { minutes }\end{array}$ & 2.06 & 645 & 12.1 & 1.07 & 53.6 & 20 & 24 & 2 \\
\hline
\end{tabular}




\begin{tabular}{|llllllllll|}
\hline & $\begin{array}{l}\text { Overview } \\
\text { Short video title }\end{array}$ & $\begin{array}{l}\text { Video } \\
\text { length } \\
\text { (minutes) }\end{array}$ & $\begin{array}{l}\text { View } \\
\text {-ers }\end{array}$ & $\begin{array}{l}\text { Watch } \\
\text { time } \\
\text { (hours) }\end{array}$ & $\begin{array}{l}\text { Average } \\
\text { view } \\
\text { duration }\end{array}$ & $\begin{array}{l}\text { Average } \\
\text { percentag } \\
\text {-e view }\end{array}$ & $\begin{array}{l}\text { Subsc } \\
\text { ribers }\end{array}$ & $\begin{array}{l}\text { Li- } \\
\text { ke }\end{array}$ & $\begin{array}{l}\text { Disl } \\
\text {-ike }\end{array}$ \\
\hline $\begin{array}{l}\text { Using multimedia for education } \\
\text { (one minute funny video) }\end{array}$ & 0.75 & 128 & 1.1 & 0.32 & 56.7 & 1 & 2 & 1 \\
\hline Profile new trend in assessment & 1.48 & 129 & 1.8 & 0.51 & 47.4 & 0 & 8 & 0 \\
\hline $\begin{array}{l}\text { Guidelines for writing R type } \\
\text { MCQs }\end{array}$ & 2.31 & 195 & 3.6 & 1.07 & 44.6 & 4 & 5 & 0 \\
\hline Tips for writing A type MCQs & 4.32 & 243 & 6.3 & 1.34 & 34.8 & 1 & 2 & 0 \\
\hline Strategies of online assessment & 3.46 & 101 & 2.3 & 1.23 & 36.7 & 0 & 2 & 0 \\
\hline Mean & 2.9 & 241.1 & 5.1 & 1.1 & 42.8 & 6.4 & 9.7 & 0.3 \\
\hline SD & 1.2 & 157.8 & 3.3 & 0.4 & 7.9 & 7.4 & 8.0 & 0.7 \\
\hline
\end{tabular}

*Watch time: estimated total hours of audience viewing time of the content, SD: standard deviation.

Table 3: The descriptive data of long VBLs.

\begin{tabular}{|c|c|c|c|c|c|c|c|c|}
\hline \multirow[b]{2}{*}{ Long video title } & \multicolumn{3}{|l|}{ Overview } & \multicolumn{2}{|c|}{ Audience retention } & \multicolumn{3}{|c|}{ Engagement } \\
\hline & $\begin{array}{l}\text { Video } \\
\text { length } \\
\text { (minutes) }\end{array}$ & $\begin{array}{l}\text { View } \\
\text {-ers }\end{array}$ & $\begin{array}{l}\text { Watch } \\
\text { time } \\
\text { (hours)* }\end{array}$ & $\begin{array}{l}\text { Average } \\
\text { view } \\
\text { duration }\end{array}$ & $\begin{array}{l}\text { Average } \\
\text { percenta } \\
\text {-ge view }\end{array}$ & $\begin{array}{l}\text { Subs- } \\
\text { cribe } \\
\text {-rs }\end{array}$ & $\begin{array}{l}\text { Li- } \\
\text { ke }\end{array}$ & $\begin{array}{l}\text { Disl- } \\
\text { ike }\end{array}$ \\
\hline $\begin{array}{l}\text { Online assessment part I Al } \\
\text { Azhar University, College of } \\
\text { Medicine }\end{array}$ & 133.2 & 28 & 0.9 & $1: 57$ & 1.5 & 0 & 2 & 0 \\
\hline $\begin{array}{l}\text { Introduction to clinical } \\
\text { biochemistry laboratory part I }\end{array}$ & 41.3 & 29 & 1.8 & 3.48 & 9.2 & 1 & 0 & 0 \\
\hline $\begin{array}{l}\text { Competencies of online teaching } \\
\text { webinar }\end{array}$ & 88.5 & 13 & 1.7 & 7.4 & 8.6 & 0 & 1 & 1 \\
\hline $\begin{array}{l}\text { Part II Introduction to } \\
\text { biochemistry lab }\end{array}$ & 43.03 & 17 & 1.1 & 3.49 & 8.9 & 0 & 0 & 0 \\
\hline Liver function test part III & 15.39 & 18 & 0.4 & 1.1 & 7.5 & 0 & 0 & 0 \\
\hline Liver function part 1 & 23.2 & 19 & 0.9 & 2.46 & 8.7 & 2 & 0 & 0 \\
\hline Rubric design & 59.38 & 79 & 3.7 & 2.48 & 4.7 & 0 & 2 & 0 \\
\hline $\begin{array}{l}\text { Performance assessment and } \\
\text { rubric design part } 1\end{array}$ & 49.2 & 47 & 3.5 & 4.24 & 8.9 & 3 & 1 & 0 \\
\hline $\begin{array}{l}\text { Competencies of online teaching } \\
\text { (Tanta University) }\end{array}$ & 55.51 & 117 & 7.9 & 4.03 & 7.3 & 8 & 5 & 0 \\
\hline $\begin{array}{l}\text { Google account not just e mail- } \\
\text { using Google drive }\end{array}$ & 15.23 & 13 & 0.6 & 2.44 & 17.8 & 0 & 1 & 0 \\
\hline Using zoom for virtual meeting & 15.36 & 347 & 18.4 & 3.1 & 30.5 & 5 & 9 & 0 \\
\hline $\begin{array}{l}\text { The roles and establishment of } \\
\text { assessment unit }\end{array}$ & 13.36 & 145 & 6.2 & 2.33 & 18.9 & 4 & 10 & 0 \\
\hline Writing learning outcomes & 13.35 & 55 & 1.1 & 1.14 & 9.2 & 0 & 1 & 0 \\
\hline Mean & 43.5 & 71.3 & 3.7 & 2.9 & 10.9 & 1.8 & 2.5 & 0.1 \\
\hline SD & 34.1 & 89.2 & 4.8 & 1.7 & 7.2 & 2.5 & 3.3 & 0.3 \\
\hline
\end{tabular}

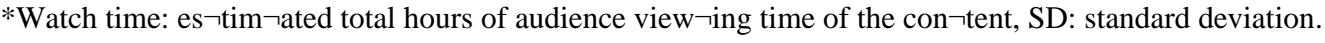

Table 4: Comparison of the mean audaince retention and engagement between short and long VBLs.

\begin{tabular}{|c|c|c|c|c|}
\hline \multirow{3}{*}{ Group } & \multicolumn{2}{|c|}{ Audience retention and engagement } & \multirow{2}{*}{\multicolumn{2}{|c|}{$t$-test }} \\
\hline & Short VBLs & Long VBLs & & \\
\hline & Mean \pm SD & Mean \pm SD & $t$ & P value \\
\hline Average view duration & $1.1 / 2.9 \pm 0.4$ & $2.9 / 43.5 \pm 1.7$ & -3.67 & $0.003 *$ \\
\hline Average percentage view (\%) & $42.8 \pm 7.9$ & $10.9 \pm 7.2$ & 9.65 & $0.000 *$ \\
\hline Subscribers & $6.4 \pm 7.4$ & $1.8 \pm 2.5$ & 1.8 & 0.106 \\
\hline Like & $9.7 \pm 8.0$ & $2.5 \pm 3.3$ & 2.55 & $0.03 *$ \\
\hline Dislike & $0.7 \pm 0.3$ & $0.1 \pm 0.3$ & 3.85 & $0.004 *$ \\
\hline
\end{tabular}




\section{DISCUSSION}

During the COVID-19 pandemic and the use of online strategies and platforms as learning and training tools for teaching undergraduates and postgraduates as well as faculty training programs becomes mandatory. The use of asynchronous e-learning using free online resources in addition to the learning management system (LMS) in place was a planned measure to overcome the suspended face-to-face training to ensure flexibility which drove participation with the emerge of the new paradigm of "online-only" education and training. ${ }^{6,8}$

In the current study, video-based lectures(VBLs) was the tools that are used in YouTube channel as we mention before YouTube is considered as the most accessible and easy educational video-sharing platforms. ${ }^{9}$ There are a total of 21 VBLs in our channel with viewers from many countries used it but the majority of them are Saudis and then Egyptians which presented our target audience.

The internet-based learning tools have become a fundamental part of medical education as these tools have the opportunities to provide more sustainability towards up-to-date learning tasks. This could explain the importance and usefulness of internet-based learning and multimedia in health professional education development. ${ }^{10}$ The use of videos for educational and training purposes has been found successful. It provides audio-visual support for learners and trainees as they can receive their learning needs through videos in the form of VBLs. These VBLs provide versatility in the representing of the learning material in a very simple way that can be repeated several times which is considered as an option not provided in the face-to-face sessions. All of these causes proved the usefulness of VBLs in teaching and training. ${ }^{10,11}$

In the current study, the number of viewers and watching time duration as well as the number of subscribers, likes, and dislikes could provide evidence of the success of VBLs as a training tool for faculty development (as they our targeted audience of the prepared videos). These VBLs are considered beneficial self-learning resources for the dynamic state of training and gain of educational skills by the viewers. Besides, the trainee has the opportunity to manage his time. ${ }^{12}$ Moreover, the positive comments that are recorded are another evidence of VBLs' success. ${ }^{13}$

In 2018, the level of helpfulness of different types of training and support, as well as the skills and needs for conducting online learning healthcare courses, were assessed by Elsamanoudy et al. ${ }^{14}$ Organizing comprehensive faculty development training courses for staff members to help them in conducting their online courses or converting their face-to-face courses to blended courses effectively was an important conclusion and recommendation in their research. This recommended task could be the responsibility of the medical education department and e-learning unit at the schools of medicine.
In 2018, Hassanien and Abou-Kamer discussed the use of video-based lectures (VBLs) as a tool for faculty development in medical education..$^{15}$ In their study, they concluded that VBLs is a valuable tool for faculty development in medical education with mandatory use of a variety of software programs and applications which are available and are helping to facilitate the process of VBL production, especially YouTube as it is considered as the most accessible video-sharing platforms. But surprisingly, they found that the long videos have unsatisfactory retention time with average view duration and the Final audience retention.

This observation opened a question; do long video lectures and presentations differ from short video ones? So, to adopt the situation of the COVID-19 pandemic and the obligatory use of online learning tools for faculty training and development, the current study mainly delivered both types of training methods (long and short video-based lectures) for faculty development and compared both types to evaluate the effectiveness of each of them as a training tool during COVID-19 pandemic (2019-2020).

In the current study, the descriptive data of short VBLs and those of long VBLs, as well as the comparison between them regarding audience engagement and retention, indicate that short VBLs are more preferable than long VBLs by the trainees in the field of faculty development.

This provides evidence to support that short VBLs from an attention perspective and to a little extent from a learning outcome perspective is more preferable than long VBLs by the audience. ${ }^{16}$

In our point of view, the short VBLs is more preferable than long one due to proposed advantages of the short VBLs in faculty training as it could be a more convenient method for adult learning(andragogy) and training -our target audience- as they mostly have no time to spend in long VBLs and can tailor their time accordingly. Moreover, short VBLs are more suitable good for faculty to be able to concentrate as it is mostly enforced by the visual and auditory aids in a short time, so it's easier to concentrate. The availability of these video-based lectures provided more chances to revisit these lectures without boring at any time even by using their smartphones with more flexibility. Lastly, the opportunity for active participation and communication is high in short VBLS. The findings of the current study confirm the results that are previously published by Ranasinghe and Wright (2019) and Tanis (2020). ${ }^{17,18}$

\section{CONCLUSION}

Based on the results of the comparing short versus long VBLs, we could conclude that short VBLs are more effective and efficient as a regard audience retention and audience engagement. In addition, the more use of advanced technology and recent software for video development makes it more attractive and engaging. The 
use of the provided information from learning analytics in video host applications like YouTube is a great source for data collection and analysis which help and support researchers in evaluating the quality of their VBLs.

Funding: No funding sources

Conflict of interest: None declared

Ethical approval: Not required

\section{REFERENCES}

1. Burgess A, Matar E, Neuen B, Fox GJ. A longitudinal faculty development program: supporting a culture of teaching. BMC Med Educ. 2019;19(1):400.

2. Steinert Y. Medical Education and Faculty Development. In: The Wiley Blackwell Encyclopedia of Health, Illness, Behavior, and Society. 2014.

3. Leslie K, Baker L, Egan-Lee E, Esdaile M, Reeves S. Advancing faculty development in medical education: a systematic review. Acad Med. 2013;88(7):1038-45.

4. Singh K, Srivastav S, Bhardwaj A, Dixit A, Misra S. Medical Education During the COVID-19 Pandemic: A Single Institution Experience. Indian Pediatr. 2020 Jul 15;57(7):678-9.

5. Armstrong K. Online discussions: Developing insight through synchronous and asynchronous conversation. Ubiquitous Learn. 2011.

6. Pal D, Patra S. University Students' Perception of Video-Based Learning in Times of COVID-19: A TAM/TTF Perspective. Int J Hum Comput Interact. 2020.

7. Boster FJ, Meyer GS, Roberto AJ, Inge C, Strom R. Some effects of video streaming on educational achievement. Commun Educ. 2006;45(1):46-62.

8. Telang A. COVID-19 drives innovation using free online resources. J Dent Educ. 2020.

9. Scholars' YouTube channels: content analysis of educational videos. Internet Latent Corpus J. 2012.

10. Ahmad T, Sattar K, Akram A. Medical professionalism videos on YouTube: Content exploration and appraisal of user engagement. Saudi J Biol Sci. 2020;27(9):2287-92.

11. Howick J. The Philosophy of Evidence-Based Medicine. 1st edition. BMJ Books. 2011.

12. Duvivier RJ, van Geel K, van Dalen J, Scherpbier AJ, van der Vleuten CP. Learning physical examination skills outside timetabled training sessions: what happens and why? Adv Health Sci Educ Theory Pract. 2012;17(3):339-55.

13. Rabee R, Najim M, Sherwani Y, Ahmed M, Ashraf M, Al-Jibury O, Rabee N, Najim R, Ahmed A. YouTube in medical education: a student's perspective. Med Educ Online. 2015;20:29507.

14. Elsamanoudy AZ, Abou-Kamer R, Ghoneim FM, ElSaadany S, Soliman MA, Hassanien MA. Faculty development needs assessment for online teaching. Int J Community Med Public Heal. 2018;5(12):5063.

15. Hassanien MA, Abou-Kamer RA. YouTube Videos as a Tool for Faculty Development in Medical Education: A Learning Analytic Overview. MedEdPublish. 2018;7(2):1-15.

16. Wilson K, Korn JH. Attention during Lectures: Beyond Ten Minutes. Teach Psychol. 2007;34(2):85-9.

17. Ranasinghe L, Wright L. Video lectures versus live lectures: competing or complementary? Med Educ Online. 2019;24(1):1574522.

18. Tanis CJ. The seven principles of online learning: Feedback from faculty and alumni on its importance for teaching and learning. Res Learn Technol. 2020;28.

Cite this article as: Elsamanoudy AZ, Aboukamer RA, Hassanien MA. Short versus long video-based lectures as a tool for faculty development during COVID-19 pandemic. Int J Community Med Public Health 2021;8:2576-81. 